\title{
Temporal Modelling of Producer Price Inflation Rates of Ghana
}

\author{
Francis Okyere ${ }^{1}$, Leonard Kyei ${ }^{2}$ \\ ${ }^{\text {I}(D e p a r t m e n t ~ o f ~ S t a t i s t i c s, ~ S c h o o l ~ o f ~ G r a d u a t e ~ S t u d i e s, ~ U n i v e r s i t y ~ o f ~ G h a n a, ~ P . ~ O . ~ B o x ~ L G ~ 571, ~ L e g o n, ~ A c c r a, ~}$ \\ Ghana) \\ ${ }_{2}^{2}$ (Mathematics Applications Department, Wisconsin International University College, P.O. Box LG 751,Legon, \\ Accra, Ghana)
}

\begin{abstract}
Producer Price Indices are a key of economic indicator in most countries and price instability introduces uncertainty into economic analysis and decision making. This paper empirically models the monthly producer price inflation rates from the year 2009 to 2013 using ARIMA model and the data was obtained from the website of Ghana Statistical Service. From the results, it is revealed that ARIMA $(1,1,1)$ is appropriate for modeling the producer price inflation rates of Ghana with a maximum log likelihood value of -163.34 , and least AIC value of 332.68, AICc value of 333.11, BIC value of 338.91 and MAE value of 2.455111. An ARCH LM test and Ljung-Box test on the residuals of the model revealed that the residuals are free from heteroscedasticity and serial correlation respectively. Hence, it is adequate for forecasting the producer price inflation rates of Ghana.

Keywords: ARIMA, Ghana Statistical Service, Modelling, Producer Price Index
\end{abstract}

\section{Introduction}

There is a general public interest in knowing the extent to which the prices of goods and services have risen. Also, it has long been customary in many countries to adjust levels of wages, pensions, and payments in long term contracts in proportion to changes in relevant prices, a procedure known as index linking or contract escalation [9].

In practice, the government agency that is given the responsibility to compile and publish Producer Price Index (PPI) is usually either the statistics office or bureau, or the central bank. This is that Producer Price Index (PPI) is seen as a major indicator of domestically induced inflation, which most central banks want to control using instruments of monetary policy [9].

According to Ghana Statistical Service the Producer Price Index (PPI) measures the average change over time in the prices received by domestic producers for the production of their goods and services [15].

PPIs are usually compiled monthly, although some countries compile them only quarterly. Countries also try to publish them as soon as possible after the end of the month to which they refer, sometimes within two weeks of the reference month. Moreover, most countries prefer not to revise them once they have been published. In contrast to many other kinds of statistics, most of the required data, at least on prices, can be collected at the same time [9].

The PPI provides a weighted average of the price changes in a group of products between one time period and another. The average price change over time cannot be directly observed and must be estimated by measuring actual prices at different points in time. Price index numbers are compiled from the collected price observations through time; their significance lies in a series of index numbers referencing the comparison prices between a particular period and a reference base. For an index to provide information on price changes, at least two index numbers from the same series need to be available, and these index numbers must relate to the same basket of goods. The PPI does not attempt to measure the actual level of prices but is limited to the measurement of the average change in prices from one period to another [9].

The PPI does not measure the value of production or cost of production, but it can be used to measure either the change in output prices owing to changes in the basic prices received by producers or, alternatively, the change in prices paid by producers for inputs of goods and services used in the production of output. There is no unique PPI, since the prices of different combinations of goods and services do not all change at the same rate. Relative prices are changing all the time, with some prices rising and others falling. Because price changes can vary considerably from product to product, the value of the price index will be dependent on the precise set of goods and services selected. It will also depend on the weights attached to the different kinds of product within the set [9].

In general terms a PPI can be described as an index designed to measure the average change in the price of goods and services either as they leave the place of production or as they enter the production process. Thus, producer price indices fall into two clear categories: input prices (that is, at purchaser prices) and output prices (that is, at basic or producer prices) [9].

It would be natural to expect that shocks to producer prices, as they spill over through the production chain, should eventually have some effect on consumer prices. This should hold true for cost-push shocks that 
are expected to appear initially during the first stages of the production chain. As a consequence, one should expect producer prices to cause consumer prices from a statistical perspective. Following these considerations, information on producer prices could therefore be useful for central banks in identifying cost-push shocks and improving forecasts of consumer prices inflation. The international experience, however, seems to suggest that the connection between producer and consumer prices is not as close as the abovementioned rationale would imply.

For example, empirical studies for the United States, such as those by Clark and Blomberg and Harris, find that the producer price index (PPI) does not have a significant predictive content for the future pattern of the consumer price index (CPI) [12][16]. For Canada, Dion studies several core inflation indicators and finds some evidence that the industrial PPI for electrical products "contain signaling information that might be useful for monitoring purposes [10].

The lack of robust evidence concerning a close causal link between the PPI and the CPI, along with the fact that most central banks define their inflation targets in terms of a certain measure of consumer prices, has led some central bankers to disregard the PPI as a relevant indicator for assessing inflationary pressures.

In general, the range of prices included in both producer and consumer price indices differs significantly. Indeed, it is common for PPI baskets to include mainly goods, while CPI's include comprehensive sets of goods and services.

Empirical researches have been carried out in the area of modeling a univariate time series using Autoregressive Integrated Moving Average (ARIMA) models popularised by Box and Jenkins (1976). Paul et al used ARIMA model for forecasting average daily share price index of pharmaceutical companies in Bangladesh. In their study, they found the best fitted ARIMA model after considering the different type of factors such as Akaike Information, corrected Akaike information, Schwartz information, mean absolute percent error, root mean square error and absolute mean error. Their empirical results indicated that the ARIMA $(2,1,2)$ model is the best for forecasting the average daily share price indices [4].

Seneviratna and Shuhua, also used univariate time series Autoregressive Integrated Moving Average (ARIMA) model was used to forecast government twelve month Treasury bill rates in Sri Lanka over the period June, 2008 to June, 2013. Box Jenkins methodology was mainly used to build four models and different diagnostic tests and criteria were applied to select the appropriate model. The accuracy of the forecasted values was compared with Mean Squared Error (MSE) and Mean Absolute Error (MAE) and their results revealed that the best ARIMA model for the twelve month treasury bill rates is ARIMA $(1,1,2)[1]$.

Chujai et al conducted a research to find a model for forecasting the electricity consumption in a household and to find the most suitable forecasting period whether it should be in daily, weekly, monthly, or quarterly. Their analysis was performed with the ARIMA (Autoregressive Integrated Moving Average) and ARMA (Autoregressive Moving Average) models. The suitable forecasting methods and the most suitable forecasting period were chosen by considering the smallest value of AIC (Akaike Information Criterion) and RMSE (Root Mean Square Error), respectively. The result of the study showed that the ARIMA model was the best model for finding the most suitable forecasting period in monthly and quarterly and ARMA model was the best model for finding the most suitable forecasting period in daily and weekly. [8].

Inflation rate in Nigeria was forecasted by Olajide et al based on the Box Jenkins approach. Yearly data from 1961 to 2010 was used. According to the empirical results, they suggested that the ARIMA $(1,1,1)$ model is the most adequate for the inflation rate. Based on the suggested model, they predicted the inflation rate at $16.27 \%$ in the year 2010 [5].

Okyere and Mensah forecasted inflation rates of Ghana for 2014 based on the Box Jenkins approach. Monthly data from January 2009 to December 2013 was used. According to the results, they suggested that ARIMA $(1,2,1)$ model was appropriate for modelling the inflation rates with a maximum log likelihood value of -64.21, and least AIC value of 13.43, AICc value of 134.87 and BIC value of 140. 61. An ARCH-LM test and Ljung-Box test on the residuals of the models revealed that the residuals are free from heteroscedasticity and serial correlation respectively. Ghana is likely to experience a persistence increase in inflation rate with double digit hence the government should reconsider his monetary policies [2].

Al-Sahib studied the predictability of the Amman Stock Exchange (ASE) based on ARIMA model over a period of seven days. Different diagnostic tests used to perform the best fitted model and showed that the selected model is suitable for forecasting on ASE [7]. Another research based on ARIMA model has done by Nochai et al. They investigated to find a model to forecast three types of oil palm price in Thailand such as Farm price, Wholesale price and pure oil price. Non-seasonal Box Jenkins methodology is used and three models are found based on the minimum of mean absolute percentage error (MAPE). Finally they developed model for three types of palm oil price and found that models ARIMA $(2,1,0)$ for the farm price, ARIMA $(1,0,1)$ for the wholesale price, and ARIMA $(3,0,0)$ for the pure oil price [11]. 
Again, Appiah and Adetunde used the Box and Jenkins (1976) approach to model and forecast the exchange rate between the Ghana cedi and the US dollar. In their study, they found that ARIMA $(1,1,1)$ model was appropriate for forecasting, the exchange rate [14].

Finally, according to literature, another study was carried out by Nasiru and Sarpong employed an empirical approach in modelling and forecasting Inflation in Ghana using the Box-Jenkins approach. The result showed that $\operatorname{ARIMA}(3,1,3)(2,1,1)[12]$ model was appropriate for modelling the inflation rates [14].

This study therefore focused on modeling the producer price inflation rates of Ghana, to determine an appropriate time series model for predicting this producer price index (PPI). The modeling of producer price inflation rates will be useful to National accounts deflators, international organizations such as Eurostat, the OECD, IMF, and European Central Bank (ECB) for economic monitoring and comparison. It will also serve as analytical tool for businesses/researchers. This again will be valuable to the central Bank of Ghhana.

\section{Material And Methods}

This study was carried out in Ghana in May, 2014, using monthly monetary policy rates of Ghana from January 2009 to December 2013. The data was obtained from the website of the Ghana Statistical and we used $\mathrm{R}$ software for building the model. The data was modeled using Autoregressive Integrated Moving Average (ARIMA) stochastic model. An autoregressive integrated moving average (ARIMA) model is a generalization of an autoregressive moving average (ARMA) model. These models are fitted to time series data either to better understand the data or to predict future points in the series.

\subsection{Autoregressive Integrated Moving Average (ARIMA) Model}

A time series $Y_{t}$ is said to follow Autoregressive Integrated Moving Average (ARIMA) model if the $d$ th differences $\nabla^{d} Y_{t}$ follow a stationary ARMA model. There are three important values which characterize an ARIMA process [8]:

- $\quad p$, the order of the autoregressive component

- $d$, the number of differences needed to arrive at a stationary $\operatorname{ARMA}(p, q)$ process

- $q$, the order of the moving average component

The general form of the ARIMA $(p, d, q)$ is represented by a backward shift operator as

$$
\emptyset(B)(1-B)^{d} Y_{t}=\theta(B) e_{t},
$$

where the AR and MA characteristic operators are

$$
\begin{aligned}
& \emptyset_{(B)}=\left(1-\emptyset_{1} B-\emptyset_{1} B^{2}-\ldots-\emptyset_{p} B^{d}\right) \\
& \theta_{(B)}=\left(1-\theta_{1} B-\theta_{2} B^{2}-\ldots-\theta_{q} B^{q}\right)
\end{aligned}
$$

and

$$
(1-B)^{d} Y_{t}=\nabla^{d} Y_{t}
$$

where

$\emptyset$ is the parameter estimate of the Autogressive component

$\theta$ is the parameter estimate of the Moving Average component

$\nabla$ is the difference

$B$ is the Backward shift operator

$\mathrm{e}_{\mathrm{t}}$ is a purely a random process with mean zero and $\operatorname{var}\left(\mathrm{e}_{\mathrm{t}}\right)=\sigma_{\mathrm{e}}^{2}$

Estimating an ARIMA model was first approached by Box and Jenkins (1976) and according to their methodology, it follows three steps as Identification, Estimation, and Diagnostic Checking. The three steps are summarized below [8].

\subsection{Model Identification}

Identification step involves the use of the techniques to determine the values of $p, q$ and $d$. The values are determined by using Autocorrelation Function (ACF) and Partial Autocorrelation Function (PACF). For any ARIMA (p, d, q) process, the theoretical PACF has non-zero partial autocorrelations at lags $1,2, \ldots, p$ and has zero partial autocorrelations at all lags, while the theoretical ACF has non zero autocorrelation at lags $1,2, \ldots, q$ and zero autocorrelations at all lags. The non-zero lags of the sample PACF and ACF are tentatively accepted as the $\mathrm{p}$ and $\mathrm{q}$ parameters. Bad choices of $p, d$, and $q$ lead to bad models, which, in turn, lead to bad predictions (forecasts) of future values [8]. 


\subsection{Unit Root Test}

Determining whether the time series is stationary or not is a very important concept before making any inferences in time series analysis. Therefore Augmented Dickey Fuller (ADF), Phillips Perron (PP) and Kwiatkowski-Phillips-Schmidt-Shin (KPSS) tests have been used to check the stationarity of the series. The test is based on the assumption that a time series data $y_{t}$ follows a random walk [12]:

$$
\mathrm{Y}_{\mathrm{t}}=\rho_{\mathrm{y}_{\mathrm{t}-1}}+\mathrm{e}_{\mathrm{t}}
$$

Where $\rho$ is the characteristic root of an AR polynomial and $\mathrm{e}_{\mathrm{t}}$ is purely a random process with mean zero and variance $\sigma^{2}$

\subsubsection{Augmented Dickey Fuller (ADF) Test}

Dickey and Fuller (1979) ADF is a test to see if the test can reject non-stationarity. The ADF unit root test, therefore tests [12],

$\mathrm{H}_{0}: \rho=1$ (non-stationary)

versus

$\mathrm{H}_{1}: \rho<1$ (stationary)

\subsubsection{Phillips Perron (PP) Test}

Phillips and Perron (1988) PP is perhaps the most frequently used alternative to the Augmented Dickey Fuller (ADF) test. It modifies the test statistic so that no additional lags of the dependent variable are needed in the presence of serially-correlated errors. An advantage with the test is that it assumes no functional form for the error process of the variable which means that it is applicable to a very wide set of problems [12].

\subsubsection{Kwiatkowski Phillips Schmidt Sahin (KPSS) Test}

Kwiatkowski et al (1992) KPSS is a test where the null hypothesis is the other way around. It is tests to see if the test can reject stationarity. This is the reverse of PP and ADF test [12].

\subsection{Estimation of Model parameters}

After identifying the possible ARIMA models, the maximum likelihood method is used to estimate the model parameters.

\subsection{Diagnostic Checking}

The next step is to select the best model among all the identified models. For this, residual diagnostics and the model with the maximum log-likelihood and minimum values of Akaike's Information Criterion (AIC), modified Akaike's Information Criterion (AICc), and Bayesian Information Criterion (BIC) was considered as the best model. Under the residual diagnostics, Ljung-Box Q statistic is used to check whether the residuals are random or not [8].

\subsubsection{Akaike's Information Criterion (AIC)}

The Akaike's Information Criterion (AIC) says to select the $\operatorname{ARIMA}(p, d, q)$ model which minimizes $[8]$,

$$
\mathrm{AIC}=-2 \ln L+2 k
$$

where $\ln L$ is the natural $\operatorname{logarithm}$ of the estimated likelihood function and $k=p+q$ is the number of parameters in the model. The AIC is an estimator of the expected Kullback-Leibler divergence, which measures the closeness of a candidate model to the truth. The smaller this divergence, the better the model [8].

A problem arises in that $\operatorname{AIC}$ is a biased estimator of the expected $\operatorname{KL}$ divergence in $\operatorname{ARMA}(p, d, q)$ models [8]. An alternative AIC statistic which corrects for this bias is

$$
\mathrm{AICC}=\mathrm{AIC}+\frac{2(K+1)(K+2)}{n-k-2}
$$

\subsubsection{Bayesian Information Criterion (BIC)}

The Bayesian Information Criterion (BIC) says to select the $\operatorname{ARIMA}(p, d, q)$ model which minimizes [8],

$$
\mathrm{BIC}=-2 \ln L+2 k \ln (n)
$$

where $\ln L$ is the natural logarithm of the estimated likelihood function and $k=p+q$ is the number of parameters in the model and $n$ is total observations.

Both AIC and BIC require the maximization of the log likelihood function and When we compared AICC to BIC offers a stiffer penalty for over parameterized models [8]. 
An overall check of the model adequacy was made using the modified Box-Pierce $\boldsymbol{Q}$ statistics. The test statistics is given by:

$Q_{m}=n(n+2) \sum_{k=1}^{n}(n-k)^{-1} r_{k}^{2} \approx \chi_{m-r}^{2}$

where:

$r_{k}^{2}=$ the residuals autocorrelation at lag $k$

$n=$ the number of residual

$m=$ the number of time lags included in the test.

When the $p$-value associated with the $\boldsymbol{Q}$ is large the model is considered adequate, else the whole estimation process has to start again in order to get the most adequate model. Here all the tests were performed at the $95 \%$ confidence interval [8].

Furthermore, a plot of the ACF squared residual and PACF squared residuals was performed on the residuals of the fitted model to check for heteroscedasticity and again an ARCH LM-test for conformity of the presence of, or otherwise ARCH effect was performed.

\subsection{Stationarity}

\section{Results And Discussion}

A behavioral analysis was carried out on the time series plot and ACF plot and partial PACF plot. The time series plot of fig. 1 shows the producer price inflation rates (PPI) of Ghana from January 2009 to December 2013 and it reveals an existence of non-significant trend. The ACF plot of Fig.1 shows the strong and slowly decaying autocorrelations with a significant spike at lag 1 of PACF plot of Fig.1. This implies that the data nonstationarity.
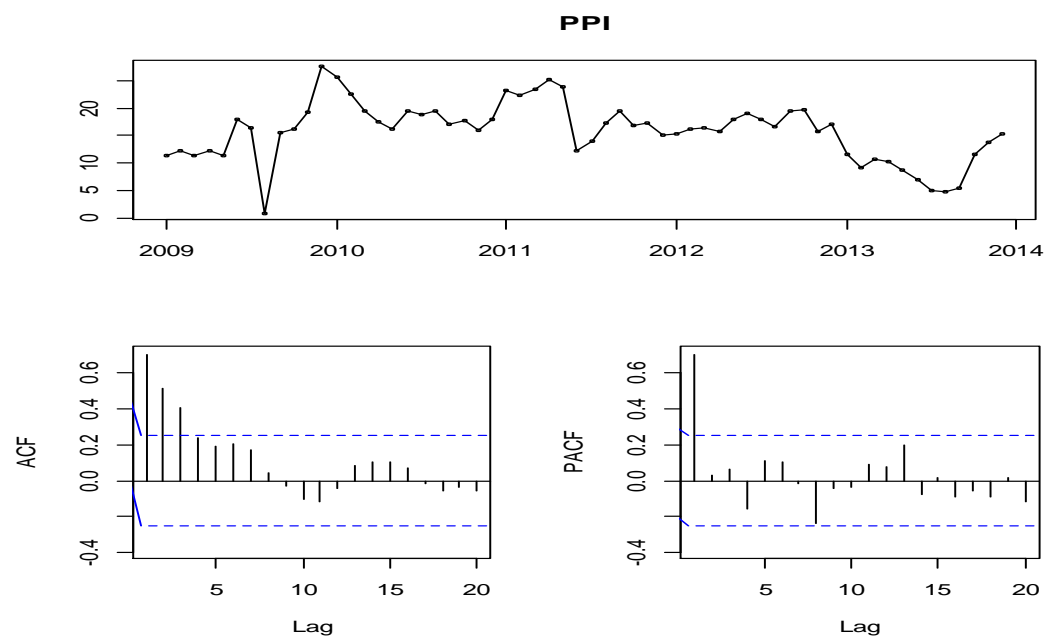

Figure 1: Time series plot and ACF and PACF plot

Table 1: Unit Root Tests Results

\begin{tabular}{|llll|}
\hline Tests & Order of Difference & Test Statistic & P-Value \\
\hline ADF & 0 & -3.1491 & 0.11 \\
\hline PP & 0 & -19.3967 & 0.06 \\
\hline KPSS & 0 & 0.6720 & 0.02 \\
\hline & & & \\
\hline ADF & 1 & -4.8291 & 0.01 \\
\hline PP & 1 & -62.4212 & 0.01 \\
\hline KPSS & 1 & 0.0502 & 0.10 \\
\hline
\end{tabular}

The ADF, PP and KPSS test further confirm the non-stationarity of the series in Table 1 but the series attain its stationarity at the first difference as shown again in Table 1. Remember that KPSS is the reverse of $\mathrm{ADF}$ and PP. 
Fig. 2 shows the Time series plot and ACF and PACF plot of the first difference of the series. Clearly, this exhibit significant trend, hence stationarity is confirm by the plots.
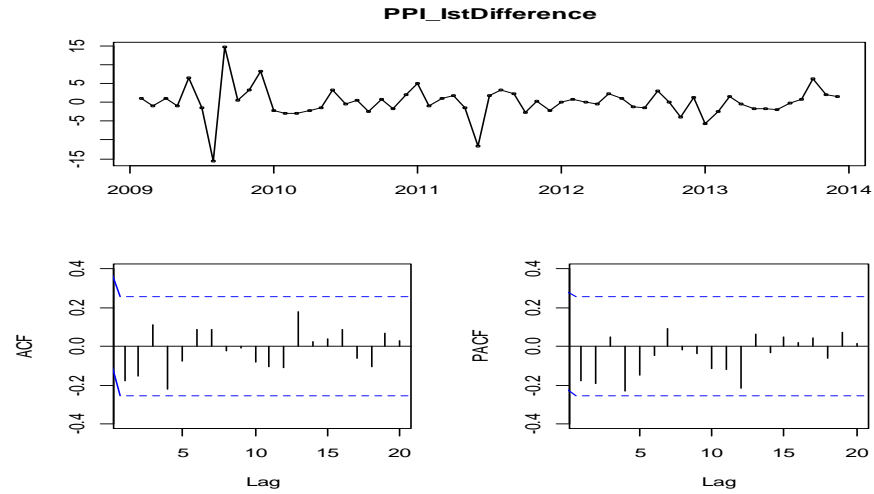

Figure 2: Time series plot and ACF and PACF plot of 1st Difference

\subsection{Model Identification}

From the results of Fig.2 and the unit root results of Table 1, this revealed that the data is stationary at the first difference. We can now propose the moving average $(q)$ component and autoregressive $(p)$ component with the significant spike to form our ARIMA model based on the ACF and PACF plot in Fig.2. By observation, there was no significant spike in both ACF and PACF plot, hence different tentative models will be propose taken into consideration of the principle of parsimony. Table 2 shows some of the suggested models.

Table 2: Different ARIMA $(p, 1, q)$ Model Fitted

\begin{tabular}{|llllll|}
\hline Model & AIC & AICC & BIC & \multicolumn{2}{l}{ Log-Likelihood } \\
\hline ARIMA(0,1,0) & 335.26 & 335.33 & $337.34^{*}$ & -166.63 & 2.566021 \\
\hline ARIMA(1,1,0) & 335.43 & 335.64 & 339.58 & -165.71 & 2.537105 \\
\hline ARIMA(1,1,1) & $332.68^{*}$ & $333.11^{*}$ & 338.91 & $-163.34 *$ & $2.455111^{*}$ \\
\hline ARIMA(2,1,0) & 335.29 & 335.72 & 341.52 & -164.64 & 2.514043 \\
\hline ARIMA(0,1,2) & 333.70 & 334.13 & 339.93 & -163.85 & 2.545682 \\
\hline ARIMA(2,1,1) & 336.29 & 337.03 & 344.60 & -164.15 & 2.590358 \\
\hline
\end{tabular}

*Best based on model selection criterion

From Table 3, ARIMA $(1,1,1)$ was the best model based on the selection criterion used. This is because it satisfies all most all the selection criterion. The parameters of this model were then estimated.

\subsection{Model Estimation}

Maximum likelihood is used to estimate the model parameters. As shown in Table 3, all the parameters were strongly significant with the exception of the constant term which happens not significant.

Table 3: Model Parameters Estimate for $\operatorname{ARIMA}(1,1,1)$

\begin{tabular}{|c|c|c|c|c|c|}
\hline Model & Component & Coefficient & S.E & Test Statistic & P-Value \\
\hline \multirow{3}{*}{$\operatorname{ARIMA}(1,1,1)$} & Constant & -0.0204 & 0.0244 & -0.84 & 0.406 \\
\hline & $\mathbf{A R}(\mathbf{1})$ & 0.6839 & 0.1023 & 6.68 & 0.000 \\
\hline & МА(1) & 0.9792 & 0.0542 & 18.06 & 0.000 \\
\hline
\end{tabular}

\subsection{Model Diagnostic}

In addition, the model was diagnosed to see how well it fits the data. It can be seen from Fig. 3 that the ACF of the residuals shows that the residuals are white noise although there was a significant spike at lag 0 of the ACF which could be due to random factor. Furthermore, the plot of the Ljung-Box p-values in Fig. 3 shows that the model was adequate for representing the data as they were above the 0.05 value indicated by the blue line. 

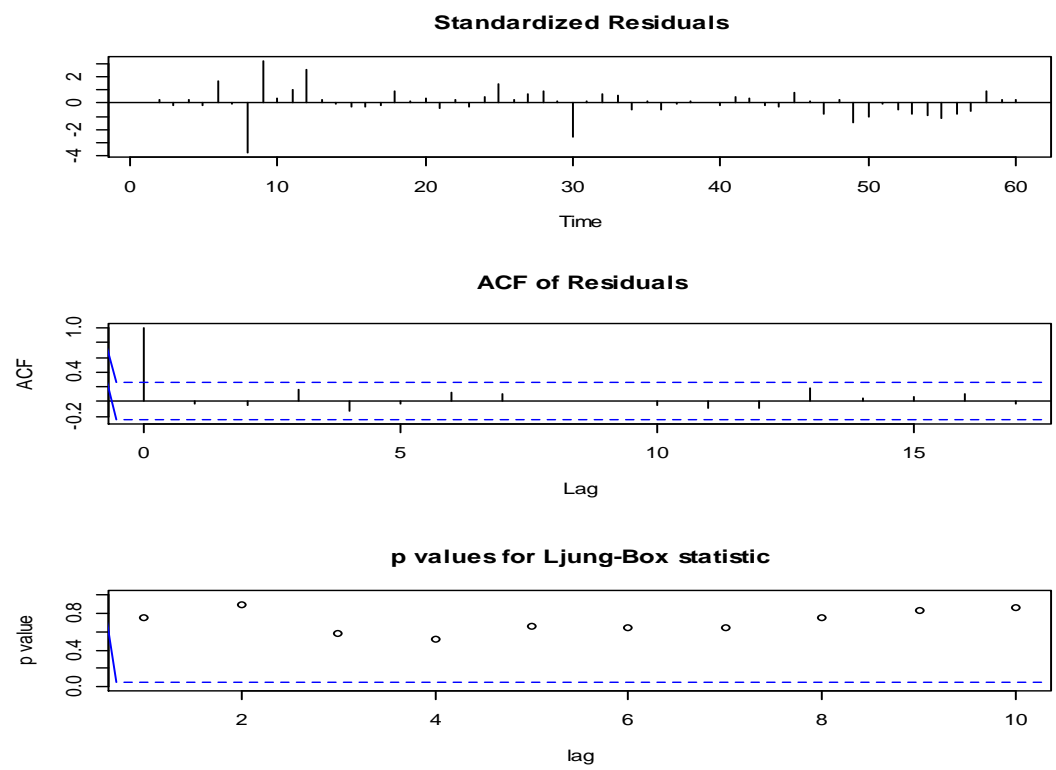

Figure 3: Diagnostic plot of residuals of $\operatorname{ARIMA}(1,1,1)$

Also, The ACF plot of Squared of Residuals, PACF plot of Squared of Residuals in Fig.4 and an ARCH-LM test in Table 4 showed that there were no ARCH effects; hence the residuals have a constant variance. The Ljung-Box p-values (> 0.05) in Fig.3 showed that there is no serial correlation in the residuals of the model. The ACF plot of the residuals in Fig. 3 also shows that the residuals are white noise series.

Table 4: ARCH LM Test for ARIMA $(1,1,1)$ of residuals

\begin{tabular}{|c|c|c|}
\hline & Chi-squared & P-Value \\
\hline 12 & 3.6184 & 0.9894 \\
\hline 24 & 25.4651 & 0.3809 \\
\hline 36 & 24 & 0.9370 \\
\hline
\end{tabular}
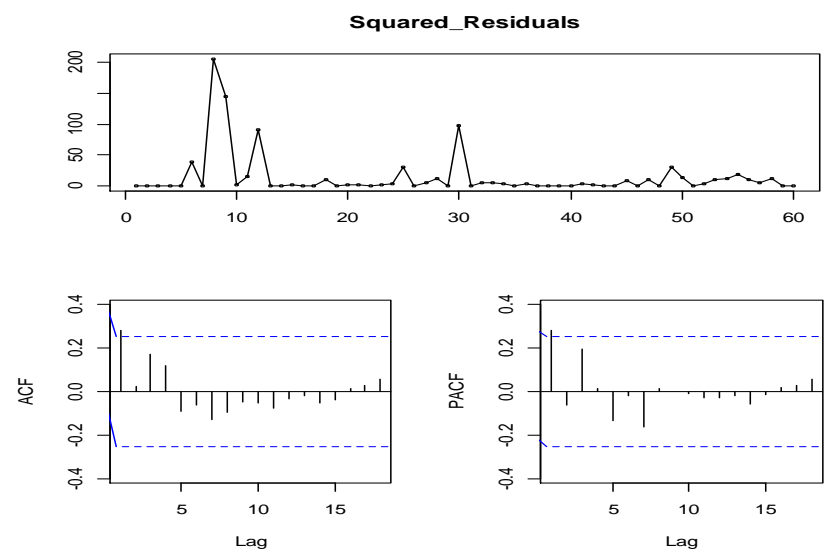

Figure 4: Diagnostic plot of squared of residuals of $\operatorname{ARIMA}(1,1,1)$

\section{Conclusion}

This study used time series to model producer price inflation rates of Ghana using data from Ghana Statistical Service (GSS) from January 2009 to December, 2013. The modeling of the producer price inflation rates was done mainly by ARIMA model. The Study revealed that the producer price inflation rates is best modeled with ARIMA(1,1,1). The diagnostics of this models showed that the model adequately fits the series hence it adequate for the forecasting of producer price index in Ghana. We believe this paper will serve as an analytical tool for businesses/researchers. 


\section{References}

[1] D.M.K.N. Seneviratna and Mao Shuhua, Forecasting the Twelve Month Treasury Bill Rates in Sri Lanka: Box Jenkins Approach, IOSR Journal of Economics and Finance (IOSR-JEF) 1(1), 2013, 44 - 47.

[2] F. Okyere and C. Mensah, Empirical Modelling and Model Selection for Forecasting Monthly Inflation of Ghana. Mathematical Theory and Modeling, 4(3), 2014, 99-106.

[3] J. M. Tebbs, STAT 520 Forecasting and Time Series (University of South Carolina, Department of Statistics, Spring, 2010).

[4] J.C. Paul, S. Hoque, and M.M. Rahman, Selection of Best ARIMA Model for Forecasting Average Daily Share Price Index of Pharmaceutical Companies in Bangladesh: A case Study on Square Pharmaceutical Ltd, Global Journal of Management and Business Research, 13(3), 2013.

[5] J.T. Olajide, O.A. Ayansola, M.T. Odusina, and I.F. Oyenuga, Forecasting the Inflation Rate in Nigeria: Box Jenkins Approach, IOSR Journal of Mathematics (IOSR-JM), 3(5), 2012, 15-19.

[6] L. Mahadeva and P. Robinson, Unit root testing to help model building (Centre for Central Bank Studies, Bank of England, 2004).

[7] M. Al-Shiab, The Predictability of the Amman Stock Exchange using the Univariate Autoregressive Integrated Moving Average (ARIMA) Model, Journal of Economic \& Administrative Sciences, 22(2), 2006.

[8] P. Chujai, N. Kerdprasop, and K. Kerdprasop, Time Series Analysis of Household Electric Consumption with ARIMA and ARMA Models, Proc. IMECS Conf., Hong Kong, 2013.

[9] Producer Price Index, Background, purpose and uses of producer price index, http://www.imf.org/external/np/sta/tegppi/ch2.pdf (Retrieved on March 15, 2014).

[10] R. Dion, Indicator Models of Core Inflation for Canada, Bank of Canada, Working paper, 1999.

[11] R. Nochai, and T. Nochai, ARIMA Model for Forecasting Oil Palm Price, Proc. 2nd IMT-GT Regional Conf. on Mathematics, Statistics and Applications, University Sains Malaysia, Penang, 2006

[12] S. B. Blomberg and E. S. Haris, The Commodity-Consumer Price Connection: Fact or Federal, Reserve Bank of New York Economic Policy Review, 1(3), 1995.

[13] S. Nasiru and S. Sarpong, Empirical Approach to Modelling and Forecasting Inflation in Ghana, Current Research Journal of Economics Theory, 4(3), 2012, 83-87.

[14] S.T. Appiah and I.A. Adetunde, Forecasting exchange rate between the Ghana cedi and the US dollar using time series analysis. Current Research Journal of Economics Theory, 3(2), 2011, 76-83.

[15] Statistical Service, Producer Price Index (PPI): PPI Press release, http://www.statsghana.gov.gh (accessed on April 20, 2014).

[16] T. Clark, Do Producer Price Lead Consumer Prices, Federal Reserve Bank of Kansas, City Economic Review , Third Quarter, 1995. 